\title{
Ecologia morfofuncional de plântulas de 15 espécies da Floresta Atlântica Sergipana, Brasil
}

Morphofunctional ecology of 15 seedlings species from an Atlantic Rainforest of Sergipe, Brazil

\author{
I. S. Matos ${ }^{1 *} ;$ M. F. Landim ${ }^{2}$ \\ ${ }^{1}$ Instituto de Biologia Roberto Alcântara Gomes/ Laboratório de Ecologia Vegetal, Universidade do Estado do Rio de \\ Janeiro, 20550-013, Rio de Janeiro - Rio de Janeiro, Brasil \\ ${ }^{1}$ Departamento de Biologia/Laboratório de Ecologia Vegetal, Universidade Federal de Sergipe, 49100-00, São \\ Cristóvão-Sergipe, Brasil \\ *ilaine.matos@gmail.com
}

(Recebido em 19 de fevereiro de 2016; aceito em 01 de julho de 2016)

\begin{abstract}
Em Sergipe a Floresta Atlântica encontra-se hoje fragmentada e reduzida a apenas 9\% da sua cobertura original. O estudo da ecologia morfofuncional de plântulas nesse ecossistema é importante para a taxonomia, silvicultura e ecologia, possibilitando a identificação das plântulas no campo, requisito necessário para o entendimento da regeneração e sucessão vegetal. Neste estudo, foram descritas a germinação e a morfologia de plântulas de 15 espécies de um remanescente florestal sergipano, sendo também analisadas as relações entre biometria das sementes, morfologia das plântulas e grupo sucessional e síndrome de dispersão. Do total de espécies analisadas $40 \%$ foram classificadas como fanero-epígeofoliáceas, 26,7\%, como cripto-hipógeo-armazenadoras, 26,7\% como fanero-epígeo-armazenadoras e 6,6\% como fanero-hipógeo-armazenadoras. A existência de relações entre a biometria da semente, o tipo morfofuncional de plântula, o grupo sucessional e a síndrome de dispersão das espécies analisadas corroborou os resultados obtidos em outras florestas tropicais, indicando que a morfologia da plântula é fortemente direcionada pelas características do nicho de regeneração.

Palavras-chave: biometria, grupo sucessional, síndromes de dispersão
\end{abstract}

Atlantic Rainforest of Sergipe State is now fragmented and reduced to only $9 \%$ of its original cover. The knowledge of seedlings' morphofunctional ecology in this ecosystem is essential to taxonomic, forestry and ecological purposes, since the ability to recognize seedlings on field is required to understand the natural regeneration and plant succession dynamics. In this study, the germination and seedlings morphology of 15 species of a Sergipe remanescent Forest were described and illustrated. Besides, relationship among seed biometry, seedling morphology, successional group and dispersion syndrome were analyzed. From the total of species analyzed $40 \%$ was classified as phanerocotylar epigeal with foliaceous cotyledons, $26.7 \%$ as cryptocotylar hypogeal with reserve storage cotyledons, $26.7 \%$ as phanerocotylar epigeal with reserve storage cotyledons and $6.6 \%$ as phanerocotylar hypogeal with reserve storage cotyledons. The relationships among seed biometry, seedling morpho-functional type, successional group and dispersion syndrome found in species analyzed are similar to those obtained in other tropical forests. This result suggests that the morphology of seedlings is strongly driven by species regeneration niche.

Keywords: biometry, successional group, dispersion syndromes

\section{INTRODUÇÃO}

A morfologia das plantas durante os estádios iniciais de desenvolvimento pode ser muito distinta dos organismos adultos. Além disso, a grande similaridade entre plântulas de espécies e gêneros afins pode dificultar, ou mesmo, impossibilitar a correta identificação dos indivíduos [1]. Desta forma, o estudo dos caracteres morfológicos das plântulas é de grande importância para a taxonomia, ampliando a quantidade de informações que podem ser utilizadas para a identificação das espécies, bem como para a resolução de problemas filogenéticos [2]. A capacidade de reconhecimento dos indivíduos que compõem o banco de plântulas também é útil nos trabalhos silviculturais e em viveiros de mudas, e fundamental para uma melhor compreensão dos processos de regeneração e sucessão natural da vegetação $[3,4]$. 
Devido à alta sensibilidade a perturbações climáticas, edáficas e antrópicas, a fase de plântula constitui o estádio mais crítico do ciclo de vida das plantas, no qual são observadas as maiores taxas de mortalidade [5]. Determinados caracteres das plântulas, principalmente aqueles relacionados aos cotilédones, como tamanho, função, posição e quantidade de reservas nutritivas, podem ser cruciais para o êxito no seu estabelecimento, e consequentemente para a perpetuação das espécies [6].

Em função do grau de exposição dos cotilédones, as plântulas podem ser classificadas em fanerocotiledonares, quando apresentam cotilédones expostos, ou criptocotiledonares, quando os cotilédones encontram-se escondidos por alguma estrutura, geralmente os tegumentos mais externos da semente [7]. Quanto à posição dos cotilédones em relação ao nível do solo, as plântulas podem ser epígeas, quando os cotilédones se elevam acima do nível do solo ou hipógeas, quando apresentam os cotilédones abaixo, ou ao nível do solo [8]. De acordo com a função exercida pelos cotilédones, as plântulas são classificadas em foliáceo-fotossintetizantes, cujos cotilédones delgados e verdes são capazes de realizar fotossíntese, ou armazenadoras, cujos cotilédones espessos contêm reservas nutritivas [9]. A combinação destes três critérios de classificação resulta em oito tipos morfofuncionais de plântulas, dos quais somente cinco foram encontrados até o momento na natureza: fanero-epígeo-foliáceo (PEF), fanero-epígeoarmazenador (PER), fanero-hipógeo-armazenador (PHR), cripto-hipógeo-armazenador (CHR) e cripto-epígeo-armazenador (CER) [10,11]. Estudos tem relatado a existência de correlações entre esses cinco tipos morfofuncionais e alguns atributos ecológicos das plantas, como grupo sucessional, síndrome de dispersão e sistema sexual. Estes resultados indicam que a morfologia das plântulas pode ter um importante significado evolutivo, funcional e ecológico, uma vez que diferenças interespecíficas no tipo morfofuncional podem refletir distintas estratégias utilizadas pelas plântulas na colonização de novos ambientes [11-15].

Apesar da grande importância para a taxonomia, silvicultura e ecologia, ainda há poucos trabalhos sobre a morfofuncionalidade de plântulas de espécies nativas do Brasil [16-25]. Diante dos altos índices de desmatamento, o estudo morfofuncional de plântulas torna-se ainda mais necessário, como subsídio para os programas de recuperação e manejo de áreas naturais [4]. Isto é particularmente verdadeiro para a Floresta Atlântica, um dos biomas brasileiros mais impactados pela ação antrópica, e que, somente na última década, perdeu quase $2.000 \mathrm{~km}^{2}$ de área florestada [26]. Em Sergipe, esta fitofisionomia que inicialmente ocupava quase $40 \%$ da área territorial do Estado, distribuindo-se, total ou parcialmente por 52 dos 75 municípios sergipanos [27], encontrase atualmente reduzida a apenas $9 \%$ da cobertura original, distribuída em uma paisagem altamente fragmentada [28].

Os objetivos deste trabalho foram: (1) caracterizar o processo de germinação e a morfologia de plântulas de espécies de um remanescente sergipano de Floresta Atlântica, fornecendo ilustrações para auxiliar na identificação; (2) avaliar a relação entre a morfologia das plântulas e alguns atributos biométricos e ecológicos das espécies.

\section{MATERIAL E MÉTODOS}

Inserida na Área de Proteção Ambiental do Litoral Sul de Sergipe (Decreto Estadual $\mathrm{n}^{\circ}$ 13.468/93), a área de estudo localiza-se no Município de Itaporanga d' Ajuda, a cerca de $30 \mathrm{~km}$ da capital Aracaju. Itaporanga d'Ajuda possui 5.695 hectares de Floresta Atlântica, sendo o terceiro município sergipano com maior área de remanescentes florestais [26]. O clima local é classificado como As pelo sistema de Köppen [29], com temperaturas médias anuais de $25^{\circ} \mathrm{C}$ e precipitação média anual de $1.463 \mathrm{~mm}$, concentrada de abril a agosto [30].

O remanescente analisado encontra-se em uma propriedade particular (Fazenda Trapsa: $11^{\circ} 12^{\prime}$ S, $37^{\circ} 14^{\prime} \mathrm{W}$ ), e constitui seis fragmentos com área total de aproximadamente 600 hectares [31]. A tipologia vegetacional predominante é a Floresta Estacional Semidecidual, que se encontra em estágio inicial ou médio de regeneração, com algumas porções de floresta madura [32]. A área possui grande importância conservacionista, pois abriga indivíduos de onça-parda (Puma concolor Linnaeus, 1771) e constitui um dos poucos habitats remanescentes para populações do macaco guigó-de-coimbra-filho (Callicebus coimbrai Kobayashi \& Langguth, 1999) e do 
macaco-prego-do-peito-amarelo (Cebus xanthosternos Wied-Neuwied, 1826), ambos em perigo de extinção [32,33].

Para a caracterização morfofuncional das plântulas foram analisadas 15 espécies, incluindo árvores, arbustos e lianas. As espécies foram selecionadas por exibirem alta frequência de ocorrência na área de estudo [31] e boa disponibilidade de frutos e sementes. Estes foram coletados manualmente a partir de pelo menos três indivíduos por espécie. Além dos diásporos, ramos férteis de cada espécie foram coletados para identificação taxonômica, com base no sistema de APGII [34], e para preparação de exsicatas [35], as quais foram depositadas nos herbários da Universidade Federal de Sergipe (ASE) e da Universidade Estadual de Feira de Santana (HUEFS).

Após o beneficiamento, de 20 a 50 sementes por espécie foram plantadas em copos plásticos contendo substrato de terra de subsolo e esterco na proporção de 3:1. Durante todo o período de desenvolvimento as plântulas foram irrigadas diariamente e mantidas sob um toldo transparente de policarbonato sob temperatura média de $25^{\circ} \mathrm{C}$. Foram consideradas germinadas as sementes em que houve protrusão da raiz, e como plântula, o período compreendido entre a protrusão da raiz até a completa expansão dos eofilos [36,37].

Para a caracterização morfofuncional foi adotado o sistema proposto por Miquel (1987) [10] e revisado por Garwood (1996) [11], o qual classifica as plântulas em: fanero-epígeo-foliáceo (PEF), fanero-epígeo-armazenador (PER), fanero-hipógeo-armazenador (PHR), cripto-hipógeoarmazenador (CHR) e cripto-epígeo- armazenador (CER). As siglas foram mantidas em inglês para facilitar a comparação com estudos similares, sendo que a primeira letra refere-se à exposição do cotilédone: criptocotiledonar $(\mathrm{C})$ ou fanerocotiledonar $(\mathrm{P})$; a segunda à sua posição: epígeo $(\mathrm{E})$ ou hipógeo $(\mathrm{H})$ e a terceira à sua função -textura: fotossintetizante $(\mathrm{F})$ ou armazenador (R). Para cada plântula foram descritas as seguintes estruturas morfológicas: raiz, hipocótilo, cotilédones, epicótilo e eofilos. As terminologias empregadas fundamentaram-se em Camargo et al. (2008) [38] e as ilustrações foram realizadas a olho nu, a partir da observação de material sadio bem desenvolvido e representativo de cada espécie.

A massa das sementes foi mensurada em balança semi-analítica (Bel Engineering, Mark 2200), enquanto que o tamanho das sementes foi determinado com paquímetro digital (IPlenna $\mathrm{d}=0,1 \mathrm{~g}$ ), medindo-se a distância entre o ápice e a base. Após a obtenção dos dados biométricos, as espécies foram classificadas em três grupos, de acordo com os valores de massa (g) (1) $\mathrm{m}<0,1 ;$; 2 ) $0,1 \leq$ $\mathrm{m} \leq 1,5$ ou (3) $\mathrm{m}>1,5$; e tamanho (cm): (1) $\mathrm{t}<0,5$; (2) $0,5 \leq \mathrm{t} \leq 2,0$ ou (3) $\mathrm{t}>2,0$. A determinação das síndromes de dispersão foi realizada com base na análise da morfologia dos diásporos, conforme van der Pijl (1982) [39], sendo as espécies classificadas dicotomicamente em abióticas (incluindo anemocóricas ou autocóricas) ou bióticas (zoocóricas). Em relação ao grupo sucessional, foram classificadas em pioneiras ou secundárias (incluindo iniciais e tardias) de acordo com informações observadas na área de estudo ou obtidas por consulta bibliográfica. Para todas as análises acima foram utilizadas de 5 a 10 indivíduos por espécie.

A existência de relação entre os tipos morfofuncionais de plântulas e as características biométricas e ecológicas foi testada através do teste de homogeneidade de $\chi^{2}$. As categorias morfofuncionais foram relacionadas com a massa e o tamanho das sementes, com o grupo sucessional e com a síndrome de dispersão. Todas as análises estatísticas foram executadas em ambiente R 3.1.1 [40].

\section{RESULTADOS E DISCUSSÃO}

\section{Caracterização morfofuncional das plântulas}

Foram descritas a germinação e a morfologia de plântulas de 15 espécies da Floresta Atlântica sergipana (Tabela 1). A classificação morfofuncional proposta por Miquel (1987) [10], apesar de simples e focada somente em características cotiledonares, englobou todos os tipos de plântulas encontradas. 
Tabela 1: Espécies da Floresta Atlântica sergipana (Fazenda Trapsa, município de Itaporanga d' Ajuda SE) classificadas de acordo com o tipo morfofuncional de suas plântulas

\begin{tabular}{lllllllllr}
\hline Espécie & Família & Hab. & N$^{\circ}$ ASE & Morf & M & T & Gs & Sd \\
\hline Tapirira guianensis Aubl. & Anacardiaceae & A & 14234 & PER & 2 & 2 & S & B \\
Annona salzmannii A. DC. & Annonaceae & A & 13018 & CHR & 2 & 2 & S & B \\
Hirtella ciliata Mart. \& Zucc. & Chrysobalanaceae & A & 13021 & CHR & 2 & 2 & S & B \\
Merremia macrocalyx & Convolvulaceae & L & 12523 & PEF & 1 & 1 & P & A \\
(Ruiz \& Pav.) O' Donell & & & & & & & \\
Abarema filamentosa Pittier & Fabaceae & A & 12291 & PER & 2 & 2 & S & B \\
Bauhinia acuruana Moric. & & Ab & 11933 & PEF & 1 & 2 & P & A \\
Bowdichia virgilioides Kunth & & A & 13011 & PER & 1 & 2 & P & A \\
Inga subnuda Salzm. ex Benth. & & A & 13981 & PHR & 2 & 2 & P & B \\
Stryphnodendron pulcherrimum Hochr. & & A & 13002 & PER & 1 & 2 & P & A \\
Coccoloba laevis Casar. & Polygonaceae & A & 13953 & PEF & 1 & 1 & P & A \\
Guettarda viburnoides Cham. \& Schltdl. Rubiaceae & A & 11116 & PEF & 2 & 2 & P & B \\
Cupania revoluta Radlk. & Sapindaceae & A & $* 17163$ & CHR & 2 & 2 & S & B \\
Paullinia trigonia Vell. & & L & 11137 & CHR & 1 & 1 & P & B \\
Serjania salzmanniana Schltdl. & & L & 12295 & PEF & 1 & 1 & P & B \\
Trigonia nivea Cambess. & Trigoniaceae & L & 13003 & PEF & 1 & 2 & P & A \\
\hline
\end{tabular}

Morf:: $\quad P E F=$ fanero-epígeo-foliáceo; $\quad P E R=$ fanero-epígeo-armazenador; $\quad$ PHR=fanero-hipógeoarmazenador; CHR=cripto-hipógeo-armazenador), massa (M: $1=m<0,1 \mathrm{~g} ; 2=0,1 \leq m \leq 1,5 \mathrm{~g}$ ) e tamanho ( $T: 1=t<0,5 \mathrm{~cm} ; 2=0,5 \leq t \leq 2,0 \mathrm{~cm}$ ) das sementes, e atributos ecológicos de hábito (Hab.: $A=$ arbóreo; $A b=$ arbustivo; $L=$ liana), grupo sucessional (Gs.: $S=$ secundária; $P=$ pioneira) e síndrome de dispersão (Sd: $A=$ abiótica; $B=$ biótica). $N^{\circ}$ ASE: Número de registro no Herbário da Universidade Federal de Sergipe. *HUEFS - Herbário da Universidade Estadual de Feira de Santana

\section{Plântulas fanero-epígeo-foliáceas (PEF)}

Bauhinia acuruana Moric. - FABACEAE (Cercideae): A emergência da plântula ocorre em média entre a terceira e a quarta semana após o plantio. A raiz é curta, reta, rígida, delgada, lisa e amarronzada (Figura 1A), com o desenvolvimento da plântula, a raiz se torna mais longa, sinuosa e espessa, e surgem raízes laterais próximas ao coleto. O hipocótilo é longo, levemente curvo, cilíndrico, espesso, liso e pubescente, ao menos na porção apical. Inicialmente branco, o hipocótilo torna-se gradativamente verde-claro à medida que se alonga. Os cotilédones são foliáceos, lisos, oblongos, com base cuneada, ápice obtuso e margens inteiras. São verdes, glabros e com nervação pinada pouco aparente (Figura 1B); os pecíolos cotiledonares são curtos, circulares, verdes e glabros. O epicótilo é longo, reto, cilíndrico, delgado, liso, pubescente e verde. Os eofilos são discolores (face adaxial verde com nervuras secundárias arroxeadas e face abaxial vinácea), coriáceos, reticulados, bifoliolados, com margens inteiras e pilosas. A nervação é acródroma, com quatro ou cinco nervuras que se originam na base da folha, e são salientes na face abaxial. Os pecíolos dos eofilos são circulares, verdes e pubescentes.

Coccoloba laevis Casar. - POLYGONACEAE: A germinação ocorre por volta da sexta à sétima semana pós-semeadura, iniciando-se pela protrusão da raiz, a qual é levemente curva, delgada, lisa e castanha, com numerosas e delgadas raízes laterais (Figura 1C). O hipocótilo é longo, curvo, cilíndrico, espesso, liso, glabro e inicialmente amarelo-esbranquiçado, tornando-se totalmente róseo à medida que se alonga. Os cotilédones foliáceos são verde-escuros, glabros, sem nervação evidente, lisos, brilhosos, hipocrepiformes com margem inteira (Figura 1D). e inserem-se na porção terminal do eixo caulinar através de pecíolos cotiledonares pequenos, 
canaliculado, róseos e glabros. O epicótilo é curto, ereto, cilíndrico, delgado, levemente rugoso, glabro e róseo. Os eofilos são foliáceos, lisos, brilhosos, glabros, simples e opostos, possuem formato orbicular, base retusa, ápice obtuso e margens inteiras. Inicialmente apresentam uma coloração arroxeada, mas à medida que se desenvolvem tornam-se verdes. Os pecíolos dos eofilos são curtos, acanalados, róseos e glabros.

Guettarda viburnoides Cham. \& Schltdl. - RUBIACEAE: A germinação ocorre por volta de cinco a seis semanas. A raiz, primeira estrutura a emergir, desenvolve-se lateralmente ao pirênio, sendo curta, delgada, lisa e esbranquiçada com raízes laterais numerosas e delgadas (Figura 1E). O hipocótilo é longo, reto, cilíndrico, espesso, liso, amarelo-esverdeado, com tricomas pequenos e esparsos. Os cotilédones são diminutos, foliáceos pilosos, oblanceolados, com base atenuada, ápice obtuso e margens inteiras (Figura 1F). São verdes, pubescentes, sem nervuras evidentes e com pecíolos também verdes e pubescentes. O epicótilo é longo, ereto, cilíndrico, espesso, liso, piloso e verde. Os eofilos são foliáceos, aveludados, simples e decussados. Possuem formato elíptico, base obtusa à retusa, ápice agudo e margens ligeiramente crenadas. São verdes, com margem, ápice e base amarronzados. Exibem nervação pinada bem evidente e tricomas densos, longos e hialinos. Os pecíolos dos eofilos são cilíndricos, amarronzados e pilosos.

Merremia macrocalyx (Ruiz \& Pav.) O' Donell - CONVOLVULACEAE: A emergência da plântula ocorre por volta da segunda à terceira semana após a semeadura (Figura 1G). A raiz é sinuosa, delgada, lisa e esbranquiçada, com raízes laterais longas e delgadas. O hipocótilo é alongado, ereto, espesso, cilíndrico, liso, glabro e inicialmente amarelado, tornando-se vináceo à medida que a plântula se desenvolve. Os cotilédones são foliáceos, lisos, hipocrepiforme e com margens inteiras. São verde-escuros, glabros e trinervados. Os pecíolos cotiledonares são alongados, acanalados, vináceos e glabros. O epicótilo é curto, ereto, delgado, liso, glabro e vináceo. Os eofilos são foliáceos, lisos, glabros, simples, palmatisectados e alternos (Figura 1H), apresentam coloração verde-amarelada a verde-escura com nervuras pinadas e margens vináceas. Os pecíolos dos eofilos são longos, acanalados, vináceos e glabros.

Serjania salzmanniana Schltdl.- SAPINDACEAE: A germinação ocorre por volta da quinta à sexta semana pós-semeadura. A raiz é sinuosa, delgada, lisa e esbranquiçada (Figura 1I). As raízes laterais inicialmente surgem da região do coleto, mas à medida que a plântula cresce elas se formam ao longo de todo o comprimento da raiz primária. O hipocótilo é longo, sinuoso, espesso, liso, glabro e branco na base, vináceo na porção mediana e verde no ápice. Os cotilédones são foliáceos, lisos, verdes, glabros, oblongos, com ápice e base obtusos, margens inteiras e nervação pinada. Os pecíolos são curtos, planos, verdes e pubescentes. $\mathrm{O}$ epicótilo restringe-se à gema caulinar. Os eofilos são foliáceos, lisos, simples, opostos, palmatilobados, trinervados, glabros e verde-amarelado (Figura 1J). Os pecíolos dos eofilos são longos, cilíndricos, verdes e pubescentes.

Trigonia nivea Cambess. - TRIGONIACEAE: A emergência da plântula ocorre por volta da quarta à quinta semana após a semeadura. A raiz delgada, lisa, branca e glabra, com raízes laterais esparsas, longas e delgadas (Figura $1 \mathrm{~K}$ ). O hipocótilo é longo, espesso, reto, cilíndrico, verde e pubescente. Os cotilédones são folicáceos, orbiculares, com base e ápice obtusos, margens inteiras e sem nervação evidente (Figura 1L), são pubescentes, verdes e com pecíolos curtos. O epicótilo é curto, espesso, cilíndrico, verde ep ubescente Os eofilos são foliáceos, simples, opostos, orbiculares, com ápice e base obtusos e margens inteiras, apresentam nervação pinada, com nervuras verde-escuras e lâmina foliar verde-amarelada na face adaxial e esbranquiçada na face abaxial. Os pecíolos dos eofilos são curtos, verdes e pilosos. 

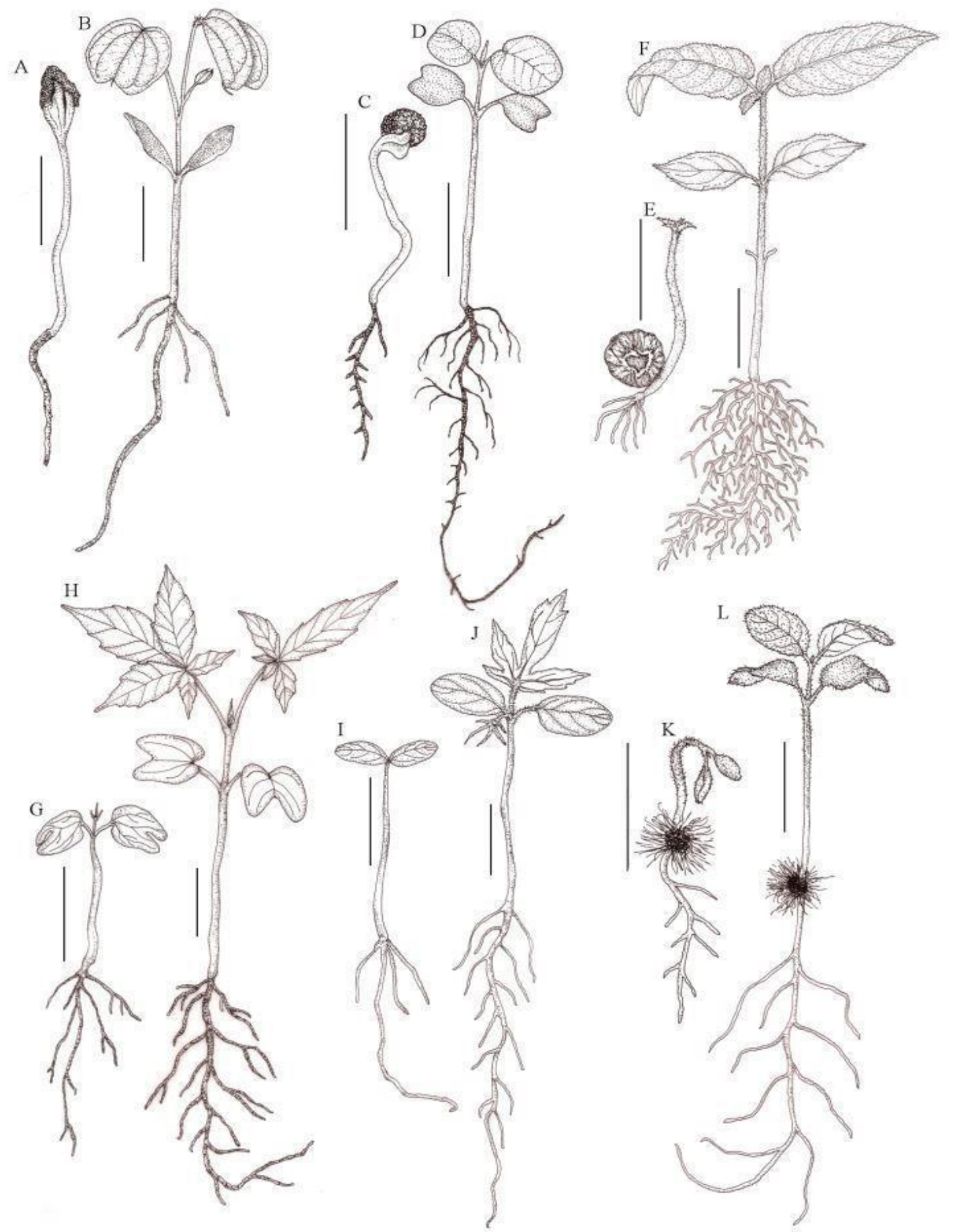

Figura 1 A-L. Plântulas fanero-epígeo-foliáceas (PEF). Bauhinia acuruana: A. 8 dias e B. 67 dias; Coccoloba laevis: C. 8 dias e D. 48 dias; Guettarda viburnoides: E. 8 dias e F. 42 dias; Merremia macrocalyx: G. 5 dias e H. 37 dias; Serjania salzmanniana: I. 10 dias e J. 32 dias; Trigonia nivea: K. 8 dias e L. 32 dias. Barras $=2 \mathrm{~cm}$. 


\section{Plântulas fanero-epígeo-armazenadoras (PER)}

Abarema filamentosa Pittier - FABACEAE (Mimosoideae): A emergência da plântula ocorre por volta da primeira à segunda semana após a semeadura. A raiz é espessa, sinuosa, lisa e branca, com raízes laterais curtas e numerosas (Figura 2A). O hipocótilo é longo, reto, cilíndrico, espesso, liso, glabro e verde-claro. Os cotilédones são carnosos, lisos, orbiculares, glabros, sésseis, verde-escuros e com margens inteiras e sem nervuras evidentes. O epicótilo é reduzido e recoberto pelos cotilédones. Os eofilos são foliáceos, lisos, opostos, e bipinados (Figura 2B). Os folíolos são verdes, glabros, ovais a elípticos, com base levemente assimétrica, ápice obtuso, margens inteiras e nervura central saliente na face abaxial.

Bowdichia virgilioides Kunth - FABACEAE (Faboideae): Apresenta período de emergência entre dez a 20 dias. A raiz é sinuosa, delgada, lisa e esbranquiçada, com raízes laterais curtas, delgadas e pouco numerosas (Figura 2C). O hipocótilo é longo, reto, cilíndrico, espesso, liso, glabro, branco na região basal e esverdeado na apical. Os cotilédones são carnosos, lisos, oblongos, glabros, verdes, com base cuneada, ápice obtuso, margens inteiras e sem nervuras ou pecíolos evidentes. O epicótilo é curto, reto, cilíndrico, delgado, liso, esparsamente pubescente e verde. Os eofilos são foliáceos, lisos, opostos, compostos e paripenados (Figura 2D). Os folíolos são elípticos, verdes, glabros, com base obtusa, ápice agudo, margens inteiras e nervura central verde-escura pouco evidente.

Stryphnodendron pulcherrimum Hochr. - FABACEAE (Mimosoideae): O período de emergência é de aproximadamente três semanas, observando-se uma baixa taxa de germinação. A raiz é sinuosa, delgada, lisa e esbranquiçada, com raízes laterais longas, delgadas e também brancas (Figura 2E). O hipocótilo apresenta-se longo, reto, delgado, cilíndrico, levemente estriado, glabro, com coloração branca na porção basal e verde-amarronzado na apical. Os cotilédones são carnosos, lisos, verdes, glabros, oblongos, trinervados, com base retusa, ápice obtuso e margens inteiras. Os pecíolos cotiledonares são curtos, aplanados, verde-amarelados e glabros. O epicótilo é longo, reto, delgado, cilíndrico, liso, glabro e verde. Os eofilos são foliáceos, lisos, alternos, compostos e paripenados (Figura 2F). Os folíolos são verdes, glabros, oblongos, com ápice e base obtusos, margens inteiras e nervação pouco evidente.

Tapirira guianensis Aubl.- ANACARDIACEAE: A emergência da raiz ocorre por volta da segunda à terceira semana pós-semeadura. A raiz é ondulada, delgada, lisa, castanhoesbranquiçada, com raízes laterais esparsas, longas e delgadas (Figura 2G). O hipocótilo é curto, curvo, cilíndrico, espesso, liso, amarelado e glabro. Os cotilédones são carnosos, lisos, glabros, lanceolados, com base obtusa, ápice mucronado, magens inteiras e sem nervação evidente. Quanto à coloração, mostram-se amarelo-alaranjados com estrias laranjas. Os pecíolos cotiledonares são curtos, espessos, glabros e amarelos. Os eofilos são foliáceos, lisos, verdes, glabros, simples, opostos, com base obtusa a cuneada, ápice apiculado, margens ligeiramente onduladas e nervação pinada (Figura $2 \mathrm{H}$ ). Os pecíolos dos eofilos são longos, aplanados, verdes e glabros.

\section{Plântulas fanero-hipógeo-armazenadoras (PHR)}

Inga subnuda Salzm. ex Benth. - FABACEAE (Mimosoideae): O período de emergência é curto, entre sete e 15 dias, sendo a taxa de recrutamento extremamente elevada e o crescimento acelerado. A raiz é espessa, lisa e esbranquiçada, com raízes laterais curtas, delgadas e esparsas (Figura 2I). O hipocótilo é curto, curvo, rugoso, espesso, pubescente e castanho. Os cotilédones são carnosos, lisos, brilhosos, glabros, marrons, orbiculares, com base retusa, ápice obtuso, margens inteiras e sem nervuras ou pecíolos. O epicótilo é longo, reto, cilíndrico, espesso, aveludado, verde-escuro e pubescente. Os eofilos são foliáceos, brilhosos, opostos, compostos e bifoliolados (Figura 2J). Os folíolos são verde-amarelados, elípticos, com base cuneada, ápice mucronado, bordos inteiros e pubescentes, e nervação pinada. As nervuras centrais são verdeescuras, espessas, pubescentes e salientes. O pecíolo do eofilo é longo, pubescente e alado. 


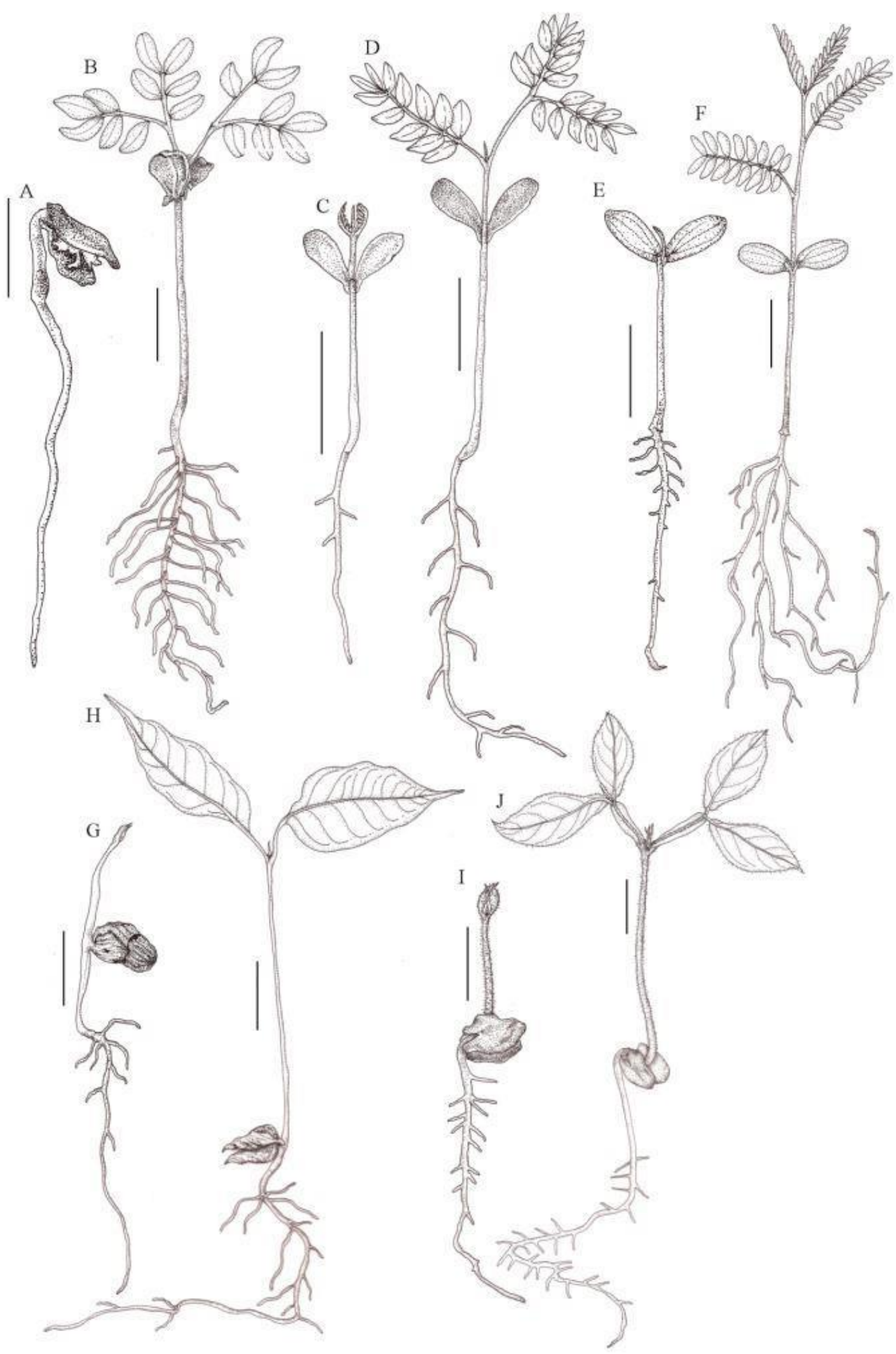

Figura 2 A-J. Plântulas fanero-epígeo-armazenadoras (PER). Abarema filamentosa: A. 8 dias e B. 32 dias; Bowdichia virgilioides: $\boldsymbol{C} .12$ dias e D. 38 dias; Stryphnodendron pulcherrimum: $\boldsymbol{E}$. 10 dias e F. 42 dias; Tapirira guianensis: G. 8 dias e H. 16 dias; Inga subnuda: I. 8 dias e J. 36 dias. Plântulas fanerohipógeo-armazenadoras (PHR). Barras $=2 \mathrm{~cm}$. 


\section{Plântulas cripto-hipógeo-armazenadoras (CHR)}

Annona salzmannii A. DC. - ANNONACEAE: A emergência da raiz ocorre por volta da sexta à sétima semana pós-semeadura. Esta é curta, curva, espessa, levemente rugosa e castanhoamarelada, com raízes laterais delgadas, longas e esparsas (Figura 3A). O hipocótilo não é alongado e os cotilédones armazenadores não são evidentes. O epicótilo é longo, curvo, espesso, glabro, com sulcos longitudinais, e com coloração que passa gradativamente de róseo-arroxeado na base a verde-escuro no ápice. Os cotilédones são foliáceos, simples, opostos, elípticos, com base obtusa, ápice agudo e bordos inteiros (Figura 3B).

Cupania revoluta Radlk.- SAPINDACEAE: A germinação ocorre entre a sexta e sétima semana pós-semeadura. A primeira estrutura a emergir é a raiz, a qual se desenvolve logo abaixo da região hilar, promovendo a abertura de uma porção da testa da semente (Figura 3C). A raiz é reta a sinuosa, delgada, lisa, branca com porções castanhas e com raízes laterais curtas, delgadas e esparsas. O hipocótilo é curto, curvo, espesso, rugoso, amarelado e glabro. Os cotilédones armazenadores não são visíveis. O epicótilo é longo, curvo, cilíndrico, delgado, liso, verde e pubescente. Os eofilos são coriáceos, lisos, brilhosos, verdes, simples, alternos, obelípticos, com base cuneada, ápice obtuso, margens denticuladas e nervuras pinadas e salientes na face abaxial (Figura 3D). Os pecíolos dos eofilos são curtos, acanalados, verdes e com tricomas curtos, brancos e esparsos.

Hirtella ciliata Mart. \& Zucc. - CHRYSOBALANACEAE: A emergência da raiz ocorre entre a quarta e quinta semana após a semeadura. A raiz é reta, delgada, lisa e castanha, com raízes laterais delgadas e esparsas (Figura 3E). O hipocótilo não é alongado e os cotilédones armazenadores permanecem protegidos pelos tegumentos da semente. $\mathrm{O}$ epicótilo é alongado, reto, cilíndrico, aveludado, espesso, pubescente e verde-claro. Os cotilédones são foliáceos, aveludados, simples, verdes, pubescentes, elípticos a cordados, com nervuras pinadas pouco evidentes (Figura 3F). Os pecíolos dos eofilos são curtos, verdes e pubescentes.

Paullinia trigonia Vell. - SAPINDACEAE: A emergência da plântula ocorre por volta da quarta à quinta semana após a semeadura. Inicialmente, ocorre a protusão da raiz, que se desenvolve logo abaixo da região hilar (Figura 3G). Esta é sinuosa, delgada de coloração castanho claro, exceto em sua porção final que é esbranquiçada. As raízes laterais são também delgadas, curtas e esparsas. O hipocótilo não é alongado, e os cotilédones armazenadores não são visíveis. O epicótilo é longo, cilíndrico, delgado, pubescente, amarelo na base e verde no ápice. Os eofilos são foliáceos, lisos, compostos, imparipenados e opostos (Figura 3H). Os folíolos são verdes, glabros, pinatilobados, com nervura pinada pouco evidente e raque levemente alada.

\section{Distribuição de frequência dos tipos morfofuncionais}

A maioria das espécies analisadas apresentou plântulas do tipo PEF (6), seguida pelas classes CHR (4), PER (4) e PHR (1), nenhuma espécie foi classificada como CER (0) (Tabela 1). A ausência deste último tipo morfofuncional pode ser explicada pela estratégia ecológica aparentemente "suicida" desse tipo de plântula, cujos cotilédones armazenadores ficam localizados acima do nível do solo, numa disposição que facilita o ataque por herbívoros. Plântulas CER apresentam, em geral, uma baixa taxa de recrutamento, tendo sido registradas apenas em espécies dos gêneros Vismia, Diospyros e Virola [10, 13], as quais não foram amostradas neste estudo. Talvez por este motivo, o tipo CER é o mais raro em florestas tropicais, atingindo uma frequência máxima de $8 \%$ na Indonésia [9].

Apesar do pequeno número de espécies analisadas, os resultados obtidos assemelham-se aos observados em outras vegetações tropicais do Brasil [13, 41, 42] e do mundo [11, 12, 14], nas quais o tipo morfofuncional PEF é quase sempre o mais frequente, variando entre $28 \%$ e $72 \%$ do total de espécies. Exceções a esse padrão foram encontradas por Okali \& Onyeachusim (1991) [43], e Baraloto \& Forget (2007) [15], os quais avaliaram plântulas em florestas tropicas da África e América do Sul e encontraram maior frequência dos tipos PER e CHR, respectivamente. Essas diferenças na abundância dos tipos morfofuncionais refletem, possivelmente, pressões seletivas distintas, relacionadas a variações nas características ecológicas, biogeográficas e 
filogenéticas de cada localidade. Por isso, os resultados obtidos em uma determinada floresta tropical não devem ser extrapolados para os trópicos como um todo.

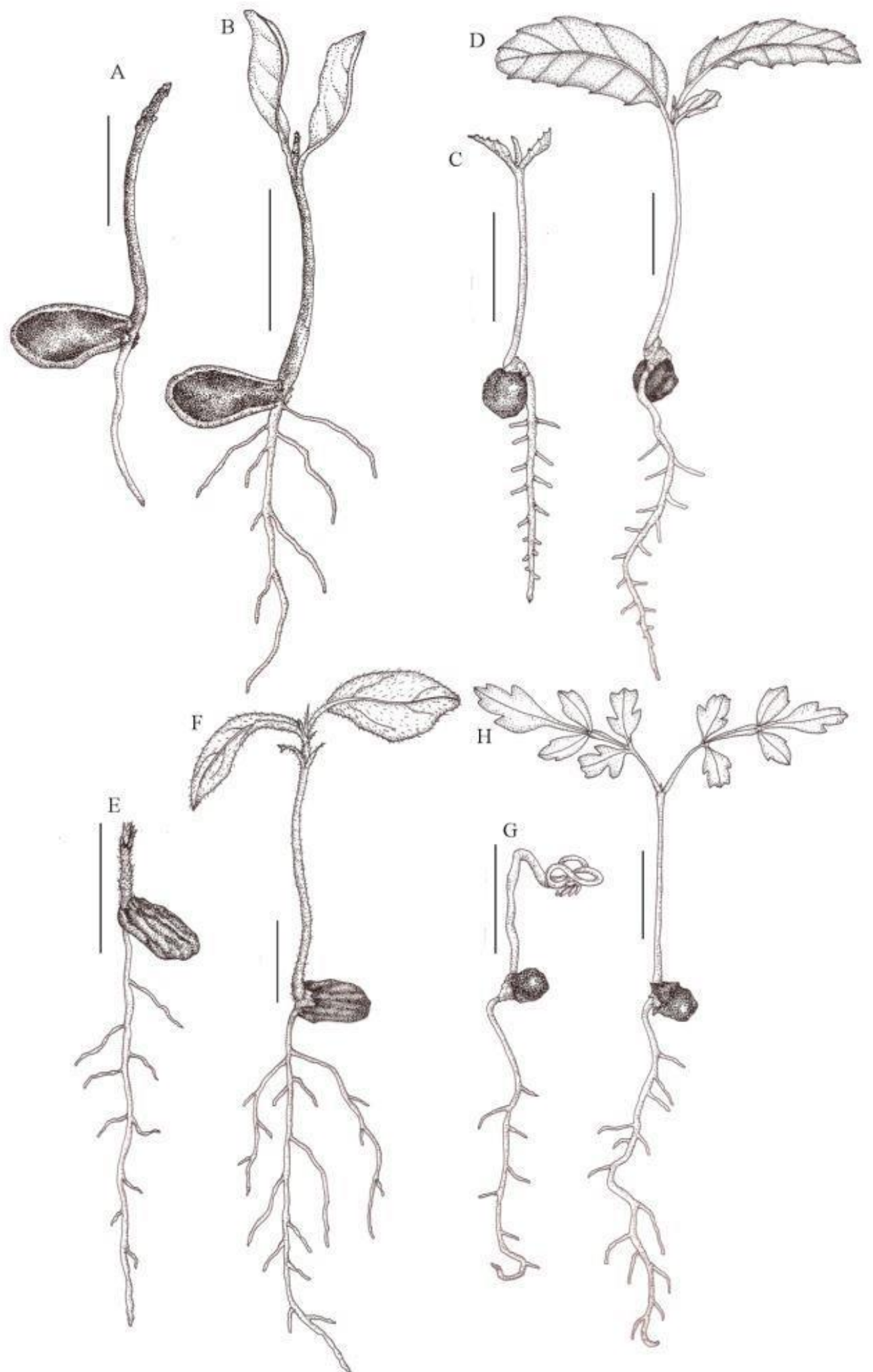

Figura 3 A-J. Plântulas cripto-hipógea-armazenadoras (CHR). Annona salzmannii: A. 12 dias e B. 68 dias; Cupania revoluta: $\boldsymbol{C}$. 8 dias e D. 36 dias; Hirtella ciliata: $\boldsymbol{E}$. 12 dias e F. 77 dias; Paullina trigonia: G. 8 dias e H.. 36 dias Barras $=2 \mathrm{~cm}$ 
Ibarra-Manríquez et al. (2001) [12], por exemplo, sugerem que devido a diferenças filogenéticas e nas taxas de regeneração natural, as regiões neo- e paleotropicais tendem a exibir distintas frequências dos tipos morfofuncionais de plântulas. Enquanto que as regiões neotropicais apresentam altas frequências dos tipos PEF e CHR, o paleotrópico exibe maior abundância dos tipos PHR, CER e PER. O grau de umidade e adversidade do ambiente também pode influenciar na distribuição dos tipos de plântulas. Segundo Lima (1989) [44], os tipos morfofuncionais fanero-epígeos (PEF + PER) são mais abundantes em matas secas e em florestas não inundáveis. Já o tipo morfofuncional CHR está mais relacionado a formações vegetais periodicamente alagáveis ou sujeitas a condições edáficas e/ou climáticas adversas, como o Cerrado $[44,13]$.

\section{Relações entre tipos morfofuncionais e atributos ecológicos}

A frequência dos quatro tipos de plântulas (PEF, PER, PHR e CHR) variou em função da massa e tamanho das sementes, bem como de acordo com a síndrome de dispersão e o grupo sucessional das espécies (Figura 4 A-D).
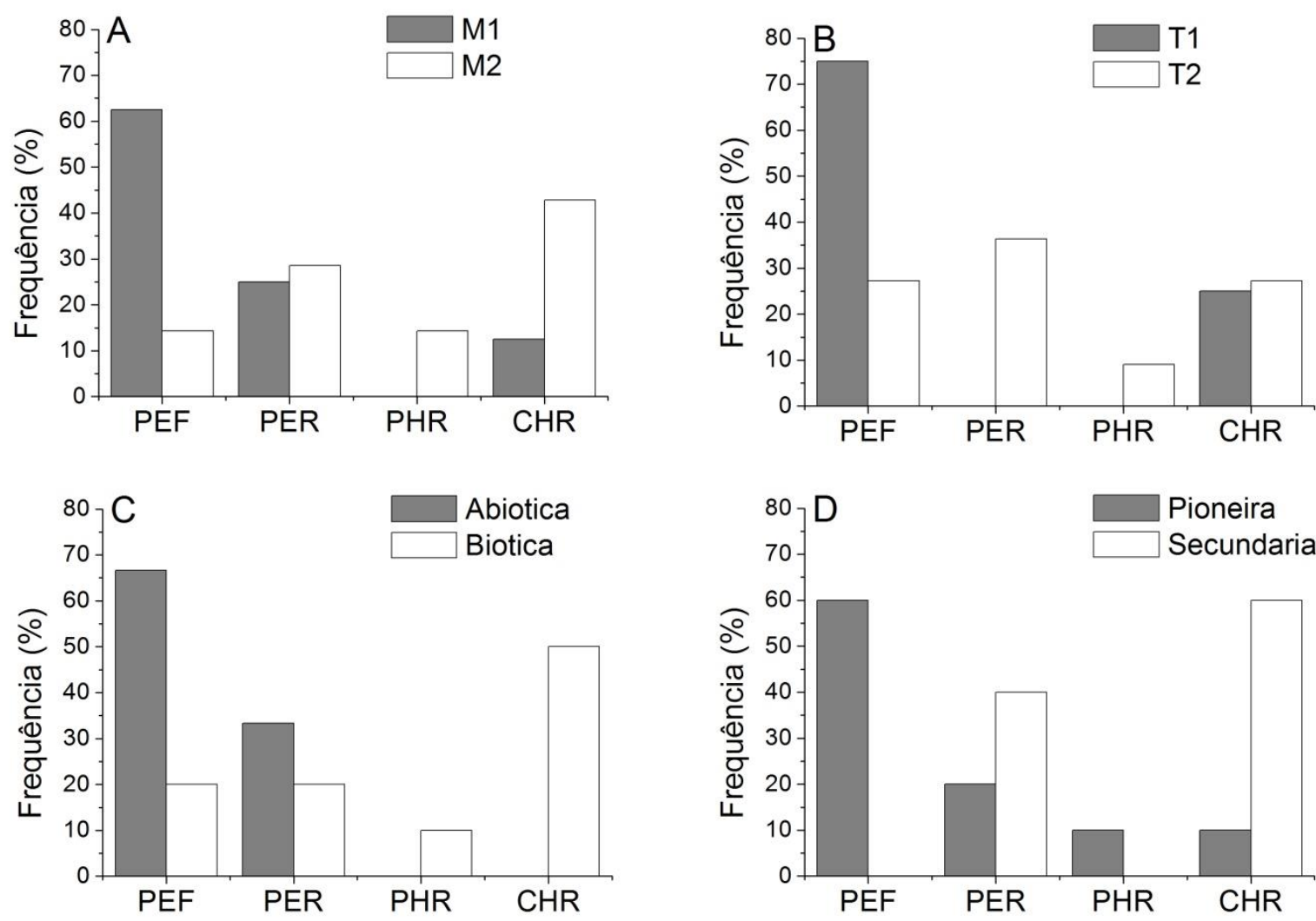

Figura. 4 A-C. Frequência relativa dos tipos morfofuncionais (PEF=fanero-epígeo-foliáceo; $P E R=$ faneroepígeo-armazenador; $P H R=$ fanero-hipógeo-armazenador; $C H R=$ cripto-hipógeo-armazenador) das plântulas de 15 espécies da Floresta Atlântica sergipana em relação $a$ : A. Massa da semente $(M 1=m<$ $0,1 \mathrm{~g} ; M 2=0,1 \leq m \leq 1,5 \mathrm{~g}) ; B$. Tamanho da semente $(T 1=t<0,5 \mathrm{~cm} ; T 2=0,5 \leq t \leq 2,0 \mathrm{~cm})$; $C$. Sindrome de dispersão (Abiótica ou Biótica) e D. Grupo sucessional (Pioneira ou Secundária).

No presente estudo, cerca de $60 \%$ das plântulas do tipo PEF foram provenientes de sementes leves $(<0,1 \mathrm{~g})$, enquanto que a maioria das espécies com sementes mais pesadas $(0,1 \leq \mathrm{m} \leq 1,5 \mathrm{~g})$ foram classificadas como CHR. Porém, comparando-se as frequências dos quatro tipos morfofuncionais entre as duas classes de massa (M1 e M2) não foram encontradas diferenças significativas $\left(\chi^{2}=5,46\right.$ e $\left.p=0,14\right)$. Plântulas do tipo PER distribuíram-se igualmente em ambas as 
classes de massa, e como houve apenas uma espécie classificada como PHR não foi possível realizar comparações para este tipo plântula (Figura. 4A). Em estudos prévios, realizados em outras florestas tropicais, tem sido observada uma relação entre a massa das sementes e a morfologia das plântulas $[12,14,15]$. Em geral, espécies com sementes leves exibem uma germinação epígea, enquanto que sementes pesadas tendem a apresentar uma germinação hipógea, principalmente devido a ausência de tecidos de sustentação nas plântulas capazes de suportar os pesados cotilédones numa posição acima do nível do solo [15]. Além disso, sementes leves produzem plântulas com cotilédones foliáceos e expostos (fanerocotiledonares), já as sementes mais pesadas originam plântulas com cotilédones armazenadores e crípticos (criptocotiledonares) [11, 12, 14, 45].

Como há uma relação direta entre massa e tamanho, sendo as sementes menores também as mais leves, resultados similares foram obtidos quando se levou em consideração o tamanho das sementes. Dessa forma, a maioria plântulas do tipo PEF (75\%) foram provenientes de sementes pequenas $(<0,5 \mathrm{~cm})$ (Figura 4B). Estudando a ecologia morfofuncional de plântulas em florestas tropicais da Malásia e do Gabão, Ng (1978) [8] e Miquel (1987) [10], respectivamente, observaram que à medida que o tamanho da semente aumenta, há uma maior proporção de plântulas criptocotiledonares e de reserva do que fanerocotiledonares e fotossintetizantes.

Ao se dividir as espécies analisadas de acordo com a síndrome de dispersão (Figura 4C), podese observar que a maioria (60\%) é dispersa por animais, e que a distribuição dos quatro tipos morfofuncionais (PEF, PER, PHR e CHR) não difere significativamente entre as diferentes síndromes de dispersão $\left(\chi^{2}=5,13\right.$ e $\left.p=0,16\right)$. De fato, espécies com plântulas PEF e PER exibem tanto dispersão abiótica (anemocórica e autocórica), quanto biótica (zoocórica). Por outro lado, todas as plântulas do tipo CHR foram provenientes de sementes zoocóricas.

O tamanho das sementes também está relacionado com a síndrome de dispersão, uma vez que sementes pequenas são predominantemente dispersas pelo vento, enquanto que sementes grandes são dispersas por animais ou por mecanismos autocóricos [39]. A predominância de dispersão por animais na classe CHR tem sido relatada em outros estudos, os quais sugerem que a zoocoria é um mecanismo de grande importância para o sucesso no estabelecimento deste tipo de plântula [12-14]. Como as espécies CHR possuem geralmente sementes grandes e pesadas, a ação de animais dispersores garante que estas sejam levadas para longe da vizinhança da planta mãe, onde a mortalidade de plântulas tende a ser elevada, em decorrência das altas taxas de predação e competição interespecífica [46, 47].

Com relação ao grupo sucessional, foram observadas diferenças significativas na distribuição dos tipos morfofuncionais de plântulas $\left(\chi^{2}=8,32\right.$ e $\left.p=0,03\right)$. Espécies pioneiras exibem predominantemente plântulas do tipo $\mathrm{PEF}$, enquanto que as secundárias ocorrem apenas nas classes PER e, principalmente, CHR (Figura 4D). Plantas pioneiras ocorrem nas bordas e clareiras das floretas. Neste tipo de ambiente a presença de cotilédones fotossintetizantes confere uma vantagem adicional, possibilitando o rápido crescimento das plântulas através do uso imediato do abundante recurso luminoso. As espécies secundárias, por sua vez, se estabelecem em ambientes sombreados, formando banco de plântulas no sub-bosque das florestas [11, 48, 49]. Nesta situação, a presença de cotilédones armazenadores compensa a baixa luminosidade, garantindo o suprimento de substâncias nutritivas para manter as plântulas vivas, mesmo sob condições de baixa capacidade fotossintética. Além disso, a presença de criptocotilédones mantém as reservas das plântulas relativamente protegidas dos danos físicos e bióticos, que tendem a ser maiores no sub-bosque do que nas áreas abertas das florestas [47, 50].

Embora as relações entre a morfologia das plântulas, a biometria das sementes e os atributos ecológicos das espécies estejam relativamente bem consolidadas [12, 14, 15], as informações sobre como os fatores ambientais podem influenciar na abundância de cada tipo morfofuncional ainda são escassas. A continuidade de estudos, através da análise de um maior número de espécies em diferentes fitofisionomias tropicais, faz-se necessária a fim de melhor esclarecer essa questão. No Brasil, embora haja vários trabalhos descrevendo a morfologia de frutos, sementes e plântulas dos diversos biomas [17-35], poucos deles classificam morfofuncionalmente as espécies avaliadas [5, 42, 51-53], ou buscam relacionar os caracteres morfológicos com a biometria das sementes e a funcionalidade ecológica das espécies [13, 41]. Este é o primeiro estudo a avaliar essas relações para plântulas da Floresta Estacional Semidecidual. 


\section{CONCLUSÃO}

A existência de relações entre a biometria da semente, o tipo morfofuncional de plântula e os atributos ecológicos das espécies da Floresta Atlântica sergipana, corroborou os resultados obtidos em outras florestas tropicais, possibilitando o seu uso para inferir os padrões de distribuição espaço-temporal das espécies ao longo do processo sucessional. Aliada a possibilidade de identificação taxonômica das plântulas no campo, essas informações são valiosas para práticas de restauração florestal, extremamente necessárias diante do atual grau de fragmentação da Mata Atlântica.

\section{AGRADECIMENTOS}

Agradecemos ao Programa Institucional de Bolsas de Iniciação Científica PIBIC-CNPq pela concessão de bolsa à I. S. Matos; à toda a equipe do Laboratório de Ecologia Vegetal, em especial ao técnico Eládio dos Santos, pela assistência durante as coletas e preparação de exsicatas e aos revisores do manuscrito pelas críticas pertinentes.

\section{REFERÊNCIAS BIBLIOGRÁFICAS}

1. Amorim IL, Ferreira RA, Davide AC, Chaves MMF. Aspectos morfológicos de plântulas e mudas de trema. Rev. bras. sementes. 2006.Abr;28(1):86-91, doi: 10.1590/S0101-31222006000100012.

2. Gurgel ESC, Santos JUM, Lucas FCA, Bastos M.NC. Morfologia de plântulas de Leguminosae e o potencial sistemático. Rodriguésia. 2012.Jan;63(1):65-73, doi: 10.1590/S2175-78602012000100006.

3. Silva MF, Goldman GH, Magalhães F M, Moreira FW. Germinação natural de 10 espécies arbóreas da Amazônia- I. Acta Amaz. 1988. Mar;18(1-2):9-26, doi: 10.1590/1809-43921988182026.

4. Leonhardt C, Bueno OL, Calil AC, Busnello Â, Rosa R. Morfologia e desenvolvimento de plântulas de 29 espécies arbóreas nativas da área da Bacia Hidrográfica do Guaíba, Rio Grande do Sul, Brasil. Iheringia. Ser. Bot.2008. Jan/Jun;63(1):5-14.

5. Fenner, M. Seedlings. New Phytol. 1987; 106:35-47.

6. Silvertown J, Franco M, Pisanty I, Mendoza. A. Comparative plant demography. Relative importance of life-cycle components to the finite rate of increase in woody and herbaceous perennials. J. Ecol. 1993. Sep; 81(3): 465-476, doi: 10.2307/2261525.

7. Duke JA. On tropical tree seedlings: I. Seeds, seedlings, systems and systematics. Ann. Missouri Bot. Gard. 1969. 56(2):125-161, doi: 10.2307/2394836.

8. Ng FSP. Tropical trees as living systems. London (UK): Cambridge University Press, 1978.Strategies of establishment in Malayan forest trees; p.129-162, doi: 10.2307/2259285.

9. De Vogel EF. Seedlings of dicotyledons: structure, development, types. Wageningen (Netherlands): Centre for Agricultural Publishing and Documentation (PUDOC), 1980.

10. Miquel S. Morphologie fonctionnelle de plantules d'espèces forestières du Gabon. Bull. Mus. Hist. Nat. 1987; 9(4):101-121.

11. Garwod NC. The ecology of tropical forest tree seedlings Paris(France): Parthenon, 1996. Functional morphology of tropical tree seedlings; p.59-129.

12. Ibarra-Manríquez G, Ramos MM, Oyama K. Seedling functional types in a lowland rain forest in Mexico. Am. J. Bot. 2001. Oct; 88(10):1801-1812.

13. Ressel K., Guilherme FAG, Schiavini I. Ecologia morfofuncional de plântulas de espécies arbóreas da Estação Ecológica do Panga, Uberlândia, Minas Gerais. Rev. bras Bot. 2004 Apr/Jun; 27:311-323, doi: 10.1590/S0100-84042004000200010.

14. Zanne AE, Chapman CA, Kitajima K. Evolutionary and ecological correlates of early seedling morphology in East African trees and shrubs. Am. J. Bot. 2005. Jun; 92(6):972-978, doi: 10.3732/ajb.92.6.972.

15. Baraloto C, Forget PM. Seed size, seedling morphology, and response to deep shade and damage in neotropical rain forest trees. Am. J. Bot. 2007. Jun;94(6):901-911.doi: 10.3732/ajb.94.6.901.

16. Araujo ECDE, Mendonça AVR, Barroso DG, Lamônica KR, Silva RFda. Caracterização morfológica de frutos, sementes e plântulas de Sesbania virgata (Cav.) Pers. Rev. bras Sementes. 2004; 26(1):105110, doi: 10.1590/S0101-31222004000100016.

17. Kuniyoshi YS. Morfologia da semente e da germinação de 25 espécies arbóreas de uma Floresta com Araucária [dissertação]. Curitiba (PR): Universidade Federal do Paraná; 1981. 233 f. 
18. Cosmo NL, Gogosz, AM, Nogueira, AC, Bona, C, Kuniyoshi, YS. Morfologia do fruto, da semente e morfo-anatomia da plântula de Vitex megapotamica (Spreng.) Moldenke (Lamiaceae). Acta Bot. Bras. 2009; 23(2):389-397, doi:10.1590/S0102-33062009000200010

19. Cosmo NL, Nogueira AC, Lima, JGL, Kuniyoshi, YS. Morfologia de fruto, semente e plântula de Sebastiania commersoniana, Euphorbiaceae. Floresta. 2010; 40(2)2:419-428.

20. Gogosz AM, Cosmo, NL, Bona, C, Souza LA. Morfo-anatômia da plântula de Campomanesia xanthocarpa O. Berg. (Myrtaceae). Acta Bot. Bras. 2010; 24(3): 613-623.

21. Gogosz AM, Boerger MRT, Cosmo NL, Nogueira AC. Morfologia de diásporos e plântulas de espécies arbóreas da floresta com Araucária no sul do Brasil. Floresta. 2015; 45(4):819-831.

22. Haliski SL, Cosmo NL, Gogosz AM, Rego SS, Nogueira AC; Kuniyoshi YS. Caracterização morfológica de frutos, sementes, plântulas e germinação de sementes de Casearia decandra. Pesq. Flor. Bras. 2013; 33:253-259.

23. Rego SS, Nogueira AC, Kuniyoshi YS, Santos AF dos. Caracterização morfológica do fruto, da semente e do desenvolvimento da plântula de Blepharocalyx salicifolius (H.B.K.) Berg. e Myrceugenia gertii Landrum - Myrtaceae. Rev. Bras. Sem. 2010; 32(3):52-60.

24. Rego SS, Cosmo NL, Gogosz AM, Kuniyoshi YS, Nogueira AC. Caracterização morfológica e germinação de sementes de Curitiba prismatica (D. Legrand) Salywon \& Landrum. Rev. Bras. Sem. 2011. 33(4): $616-625$.

25. Bassaco MVM, Nogueira AC, Cosmo NL, Avaliação da germinação em diferentes temperaturas e substratos e morfologia do fruto, semente e plântula de Sebastiania brasiliensis. Rev. Flor. 2014. 44(3):381-392.

26. Fundação SOS Mata Atlântica. 2014. Atlas dos Remanescentes Florestais da Mata Atlântica período 2012-2013. Relatório técnico. Disponível em: http://www.sosma.org.br. Acessado em 09.09.2014.

27. Campos G. Mapa florestal. Ministério da Agricultura, Indústria e Comércio. São Paulo (São Paulo): Secretaria do Estado do Meio Ambiente, 1912.

28. Santos ALC. Diagnóstico dos fragmentos de mata atlântica de Sergipe através de sensoriamento remoto. [dissertação] São Cristóvão (SE): Universidade Federal de Sergipe, 2009. 94f.

29. Alvares CA, Stape JL, Sentelhas PC, Gonçalves JLM, Sparovek G. Köppen's climate classification map for Brazil. Met. Zeitschrift. 2013;22:711-728.

30. Sergipe Informes Municipais da Secretaria de Estado do Planejamento e da Ciência e Tecnologia.. Aracaju (Brasil): Superintendência de Estudos e Pesquisas, SUPES, 2001. p. 75.

31. Souza-Alves JP, Barbosa MRdeV, Ferrari SF, Thomas WW. Diversity of trees and lianas in two sites in the coastal Atlantic Forest of Sergipe, northeastern Brazil. Cheklist. 2014.10(4):709-717, doi: 10.15560/10.4.709.

32. Chagas RRD, Ferrari SF. Population parameters of the endangered titi monkey, Callicebus coimbrai Kobayashi and Langguth, 1999, in the fragmented landscape of southern Sergipe, Brazil. Brazilian J. Biol. 2011. Aug;71(3):569-75.

33. IUCN (International Union for Conservation of Nature). 2014. The IUCN Red List of Threatened Species. 2014.2. Disponível em: http://www.iucnredlist.org. Acessado em 09.09.2014.

34. Souza VC, Lorenzi H. Botânica Sistemática: guia ilustrado para a identificação de Angiospermas da flora brasileira, baseado em APG II. 3 ed. Nova Odessa (SP): Instituto Plantarum;2012. p.630.

35. Mori SA, Silva LAM, Lisboa G, Corandin L. Manual de manejo de herbário fanerógamo. 2 ed. IlhéusItabuna (BA): Centro de Pesquisa de Cacau. 1989.

36. Hertel RJC. Estudos sobre Araucaria angustifolia. Descrição morfológica do fruto e germinação. Instituto de História Natural. 1968; p. 1-25.

37. Souza LA. Morfologia e anatomia vegetal: célula, tecidos, órgãos e plântula. Ponta Grossa (Paraná, Brasil): UEPG; 2003. $259 \mathrm{p}$

38. Camargo JLC, Ferraz IDK., Mesquita M R, Santos BA, Brum HD. Guia de propágulos e plântulas da Amazônia. Volume I. Manaus (AM): INPA.;2008.p.168.

39. Van der Pijl, L. Principles of dispersal in higher plants. Berlim (Germany): Springer-Verlag; 1982.

40. R Development Core Team. 2014. R: A language and environment for sta- tistical computing. R Foundation for Statistical Computing, Vienna, Austria. ISBN 3-900051-07-0, URL http://www.Rproject.org.

41. Maia LA, Maia S, Parolin P. Seedling morphology of non-pioneer tress in central Amazon várzea foodplain forests. Ecotropica 2005;11:1-8.

42. Lobo GA, Santana DG de, Salomão AN, Rehbein LS, Wielewicki AP. A technological approach to the morphofunctional classification of seedlings of 50 Brazilian forest species. J. Seed Sci. 2014; 36(1):87-93, dou: 10.1590/S2317-15372014000100011.

43. Okali DUU, Onyeachusim HD. Rain forest regeneration and management. Paris (France): Parthenon; 199. The ground flora and rain forest regeneration at Omo Forest Reserve, Nigeria. p. 273-283. 
44. Lima HC.Tribo Dalbergiae (Leguminosae, Papilionoideae): morfologia dos frutos, sementes e plântulas e sua aplicação na sistemática. Arq. Jard. Bot. Rio de Janeiro 1989;30:1-42.

45. Wright IJ, Clifford HT, Kidson R, Reed ML, Rice BL, Westoby M. A survey of seed and seedling characters in 1744 Australian dicotyledon species: cross-species trait correlations and correlated traitshifts within evolutionary lineages. Biol. J. Linnean Soc. 2000. Apr;69(4):521-547, doi: 10.1111/j.1095-8312.2000.tb01222.x.

46. Clark DA, Clark DB. Spacing dynamics of a tropical rain forest trees: evaluation of the JanzenConnell model. Am. Nat. 1984.Dec;124(6):769-788.

47. Clark DA, Clark DB. The impact of physical damage on canopy tree regeneration in a tropical rain forest. J. Ecol. Jun;1991. 79(2):447-458, doi: 10.2307/2260725.

48. Kitajima K.. Relationship between photosynthesis and thickness of cotyledons for tropical tree species. Funct. Ecol. 1992. 6(5):582-589, doi: 10.2307/2390056.

49. Kitajima, K. The ecology of tropical forest tree seedlings Paris (France): Parthenon, 1996. Cotyledon functional morphology, patterns of seed reserve utilization and regeneration niches of tropical tree seedlings.

50. Green PT, Juniper PA. Seed mass, seedling herbivory and the reserve effect in tropical rainforest seedlings. Funct. Ecol. 2004.Jul;18(4):539-547, doi: 10.1111/j.0269-8463.2004.00881.x.

51. Cavichiolo LE, Boeger MRT, Marques MCM. Estrutura dos eófilos e cotilédones de quatro tipos de plântulas da Floresta de Restinga, Paraná. Iheringia. Ser. Bot. 2009.Jul/Dez; 64(2):5-14.

52. Lopes A, Rosa-Osman SM da, Piedade MTF. Caracterização morfológica das plântulas de cinco espécies arbóreas da Floresta Estacional Semidecidual, Brasil. Flor. 2012.42(1):105-114.

53. Alves MCJL, Lima PB, Lima LF, Zickel CS. Morphological description to identify the seedlings of woody species, Biota Neotrop. 2013.Jul/Set;13(3), doi: 10.1590/S1676-06032013000300036. 